\title{
Authorship of Retraction Notices: "If Names Are Not Rectified, Then Language Will Not Be in Accord with Truth."
}

\author{
Guangwei Hu \\ English Language and Literature Academic Group, National Institute of Education, \\ Nanyang Technological University, Singapore 637616, Singapore; guangwei.hu@nie.edu.sg; Tel.: +65-6790-3484 \\ Academic Editor: Alan Singleton \\ Received: 22 April 2017; Accepted: 26 April 2017; Published: 2 May 2017
}

\begin{abstract}
Retraction notices appear regularly in many scholarly journals, especially top-tier journals of science and engineering. One disconcerting feature of this emergent genre is evasion of authorship, that is, the deliberate obscuring of who has authored a particular retraction notice. This communication illustrates and discusses problems of evaded authorship of retraction notices. To address these problems, it proposes that scholarly journals should require explicit authorship of retraction notices and the inclusion of core generic components such as the content to be retracted, the reason(s) for the retraction, the attribution of responsibility, and the expression of mortification.
\end{abstract}

Keywords: retraction notices; academic misconduct; obscured authorship

Whether we like it or not, retraction notices are found in many prestigious scholarly journals including such high-impact journals as Nature, Science, Cell, and The Lancet [1,2]. As a matter of fact, at the time of writing this short communication, Springer, a major international publisher of scientific research, has just retracted 107 papers from the journal Tumor Biology in a single retraction notice [3], making it "a new record" [4] (p. 1). Publications can be retracted for various reasons-fortuitous research findings that cannot be replicated and editorial blunders that have resulted in duplicate publication of the same article [5,6]. More often than not, however, published articles are retracted for various forms of academic misconduct, for example, fabrication and falsification of data, plagiarism, and image manipulation [7-9]. Research suggests that misconduct as a reason for retractions has been gaining increasing prominence [10]. The retraction of questionable publications serves the important functions of weeding out fake findings, rectifying false literature, and maintaining academic integrity. In an ongoing study, my collaborator and I are examining retraction notices as an academic written genre and the discursive rendering of authorial stance and ethical responsibility. While collecting and processing a corpus of retraction notices, we have encountered a phenomenon that is rare in other academic genres - the evasion of authorship.

The following two examples suffice to illustrate the problem:

The article "The Effects of Messiness on Preferences for Simplicity," by Jia (Elke) Liu, Dirk Smeesters, and Debra Trampe, which appeared in the June 2012 issue of the Journal of Consumer Research (vol. 39, no. 1), has been retracted. We apologize for any problems that the publication of this article may have caused [11].

Due to a mistake of duplicating the publication of original data which already appeared in Circulation Research (84: 1073-1084, 1999), the following paper published in Molecular Cellular Biochemistry has been retracted with an apology [12]. 
In both retraction notices, there are no explicit markers-for example, salutation, sign-off, unmistakable use of first-person/third-person pronouns, references to actions by the authors of retracted papers, etc.- that clearly indicate who authored the retraction notices. Although an apology is expressed in each case, it is not entirely clear who is/are apologizing. In fact, it is not even clear whether it is the authors, editors, publishers, or other parties that have retracted the published papers. This ambiguity is achieved through the use of the passive voice and nominal forms (i.e., nouns derived from verbs) that effectively efface agency by leaving out the performers of actions in question [13].

Although most of the 376 retraction notices we have collected from two disciplines (i.e., cell biology and business management) have explicitly marked the authorship (i.e., by editors/publishers, authors, or both parties) by signing off clearly or using personal pronouns unambiguously, a sizeable proportion (around 17\%) of the retraction notices have obscured authorship. The deliberate evasion of authorship, together with the use of discursive strategies such as hiding agents of misconduct through the passive voice and avoiding the expression of an authorial stance, epitomizes some of the most common responsibility-evading strategies discussed in William Benoit's (1995) image restoration theory [14], and seeks to duck ethical sanctions. As Confucius exhorted 2500 years ago, however, "if names are not rectified, then language will not be in accord with truth". In the same spirit, I suggest that scholarly journals require explicit authorship of retraction notices and the inclusion of core generic components such as the content to be retracted, the reason(s) for the retraction, the attribution of responsibility, and the expression of mortification. Such requirements are consistent with the retraction guidelines developed by the Committee on Publication Ethics [15] and serve the aforementioned ethical and substantive functions of retractions well.

Acknowledgments: This short communication is not supported by any funding. I wish to thank my collaborator, Shaoxiong $\mathrm{Xu}$, for collecting the retraction notices from the Web of Science and engaging me in many thought-provoking discussions about authorship issues found in our corpus of retraction notices.

Conflicts of Interest: The author declares no conflict of interest.

\section{References}

1. Trikalinosa, N.A.; Evangeloua, E.; Ioannidis, J.P.A. Falsified papers in high-impact journals were slow to retract and indistinguishable from nonfraudulent papers. J. Clin. Epidemiol. 2008, 61, 464-470. [CrossRef] [PubMed]

2. Chen, C.; Hu, Z.; Mllbank, J.; Shultz, T. A visual analytic study of retracted articles in scientific literature. J. Am. Soc. Inf. Sci. Technol. 2013, 64, 234-253. [CrossRef]

3. Stigbrand, T. Retraction Note to Multiple Articles in Tumor Biology. Tumor Biol. 2017. Available online: https:/ /link.springer.com/article/10.1007/s13277-017-5487-6 (accessed on 22 April 2017). [CrossRef]

4. Retraction Watch. Available online: http://retractionwatch.com/2017/04/20/new-record-major-publisherretracting-100-studies-cancer-journal-fake-peer-reviews/ (accessed on 22 April 2017).

5. Budd, J.M.; Sievert, M.; Schultz, T.R. Phenomena of retraction: reasons for retraction and citations to the publications. JAMA 1998, 280, 296-297. [CrossRef] [PubMed]

6. Moylan, E.C.; Kowalczuk, M.K. Why articles are retracted: A retrospective cross-sectional study of retraction notices at BioMed Central. BMJ Open 2016, 6, e012047. [CrossRef] [PubMed]

7. Fang, F.C.; Casadevall, A.; Morrison, R.P. Retracted science and the retraction index. Infect. Immun. 2011, 79, 3855-3859. [CrossRef] [PubMed]

8. Corbyn, Z. Misconduct is the main cause of life-sciences retractions. Nature 2012, 490, 21. [CrossRef] [PubMed]

9. Saey, T.H. Most retractions not honest errors: Science journals pull most papers for fraud, plagiarism. Sci. News 2012, 182, 13. [CrossRef]

10. Steen, R.G. Retractions in the scientific literature: Is the incidence of research fraud increasing? J. Med. Ethics 2011, 37, 249-253. [CrossRef] [PubMed]

11. Anonymous. Retraction. J. Consum. Res. 2012, 39, 444.

12. Anonymous. Retraction. Mol. Cell. Biochem. 2003, 251, 167. 
13. Lukin, A.; Butt, D.; Matthiessen, C. Reporting war: Grammar as 'covert operation'. Pac. J. Rev. 2004, 10, 58-74.

14. Benoit, W. Accounts, Excuses, and Apologies: A Theory of Image Restoration Strategies; State University of New York Press: New York, NY, USA, 1995.

15. Committee on Publication Ethics (COPE). Retraction Guidelines. Available online: https://publicationethics. org/files/retraction\%20guidelines_0.pdf (accessed on 22 April 2017). 